\title{
Analysis of Circadian Stimulus and Visual Comfort Provided by Window Design in Architecture
}

\author{
I. Acosta, J. F. Molina, and M. A. Campano
}

\begin{abstract}
Light is the major synchronizer of circadian rhythms to the 24-hour solar day. Compared to the visual system, the circadian system requires more light to be activated and is more sensitive to short-wavelength light. Daylighting is an ideal light source for circadian entrainment. Architectural and design features, such as window size and room reflectances impact the amount of circadian stimulus that the patient will receive. DaySim 3.2 simulations were used to determine the percentage of days that occupants would receive a minimum circadian stimulation of 0.50 for at least an hour during the morning. According to a phototransduction model of the human circadian system, a circadian stimulation of 0.50 is equivalent to suppressing the hormone melatonin by about $50 \%$. This circadian stimulus criterion is examined for different window to wall ratios, for two average room reflectances, and for four latitudes. The present paper provides an example of a tool that could be used to assist designers in fenestration and interior design.
\end{abstract}

Index Terms - Circadian stimulus, daylight autonomy, visual comfort, window.

\section{INTRODUCTION}

Window design is the key element for allowing natural light inside buildings [1]. The proper design of windows can also improve thermal comfort and save electric lighting energy [2]. Research efforts have investigated how windows provide daylight in a space [3], [4] in terms of the light distribution and potential lighting energy savings. Other studies evaluated shading devices [5], [6], defining the effect of blinds or overhangs, as well as the relationship of these shading devices with electric lighting [7]. Recent studies have investigated whether there is a relationship between the spectrum of daylight and health outcomes [8]. In addition, light reaching the retina has a profound effect on human health and well-being. Light is the major synchronizer of circadian rhythms to the natural light-dark cycle. Circadian rhythms in our bodies repeat at approximately $24 \mathrm{~h}$. In the absence of any external cue, human circadian rhythms will run with an average period slightly greater than $24 \mathrm{~h}$. Morning light will reset the biological clock daily and promote entrainment to the natural $24 \mathrm{~h}$ light-dark pattern.

There are many metrics related to the measurement of daylight through windows. Daylight factor is the simplest and most common measure to quantify the daylight in a space. It expresses the potential illuminance inside a room for the worst possible scenario, overcast sky conditions when there

Manuscript received December 8, 2015; revised March 23, 2016. This work was supported in part by the University of Seville.

The authors are with Instituto Universitario de Arquitectura y Ciencias de la Construcción, Universidad de Sevilla, Spain (e-mail: iacosta@us.es). is less exterior daylight [9]. Many of the studies of daylight through windows are based in this metric [10], [11]. However, there are now new dynamic metrics based on weather data, which require complex calculations through lighting simulation programs [12]. Several studies of daylighting have been developed using the dynamic metrics of daylight autonomy or useful daylight illuminance. These new metrics complement the daylight factor values, describing the daylight inside a room [13].

However, neither the daylight factor nor dynamic metrics fully describe the quality of natural light, because all of these metrics represent the quantification of light only for the visual system. Therefore, it is necessary to define a metric related to the non-visual human response to light, the human circadian system [14].The circadian stimulus is a metric which can help predict daylighting's benefits on human health [15], [16]. Using a model of photo transduction [17], the circadian light can be defined according to the daylight allowed by windows or clerestories.

Daylight is potentially the ideal light source for synchronizing our circadian systems to local time. It provides the right amount for circadian entrainment. Indeed, for millennia this was the only light source used by terrestrial species for circadian entrainment. In a modern, 24 hour society populated by people who spend most of their time indoors, it is quite reasonable to suppose that electric lighting, operated during the day and during night, blurs the distinction between day and night, compromising our entrainment to the local time [18]. In other words, without access to daylight (or electric lighting providing comparable amount, spectrum, distribution, duration, and timing), human health and well-being may be compromised. Although daylight may help patients in hospitals or care rooms [19], [20], studies to date have investigated the effect of daylight on patients' outcomes [21], [22], but have not specifically investigated the effects of daylight on the circadian system of occupants in common residential rooms according to window design.

\section{OBJECTIVES}

The main objective of this research is to determine the window size in order to deliver a proper circadian stimulus (CS) value enough to promote entrainment in residential rooms. The calculations were performed for four locations to examine the impact of different latitudes and weather conditions. The goal was to provide an example of a tool that could assist designers to select window characteristics that would provide the target CS value at occupants' eyes. 


\section{Methodology}

\section{A. Model}

The calculation model for the analysis of circadian stimulus is defined as a room $3.00 \mathrm{~m}$ wide by $6.00 \mathrm{~m}$ deep by $3.00 \mathrm{~m}$ high. The ceiling, walls and floor of the room have a thickness of $0.25 \mathrm{~m}$. A window of variable size is located in the $3.00 \mathrm{~m}$ wide façade. The double-leaf window has $0.05 \mathrm{~m}$ thick joinery and double glazing which produces a solar factor of 0.75 . The reflectance of the inner surfaces of the calculation model is variable, accordingly two basic room models -with light or dark surfaces- are defined. The inner surfaces of the room are diffuse reflectors and the Lambertian reflection of daylight is therefore directly proportional to the cosine of the angle between the observer's line of sight and the surface normal. All variables of the calculation model are shown in Fig. 1.

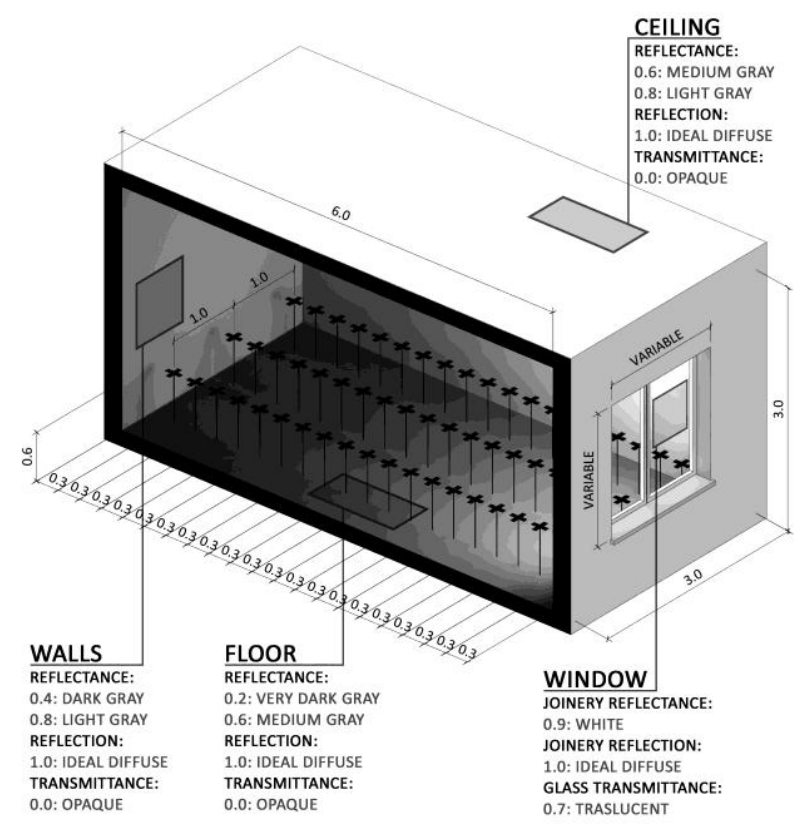

Fig. 1. Calculation model.

The measurement of circadian stimulus is performed on the axis of symmetry of the calculation model and on two equidistant axes at $1.00 \mathrm{~m}$. Therefore, the study points are located on these axes with a spacing of $0.30 \mathrm{~m}$ and a height above ground of $0.60 \mathrm{~m}$.

The calculation model is defined according to the following variables:

Window size:

10: Window to Façade ratio $10 \%$, equivalent to $0.90 \mathrm{~m}^{2}$.

20: Window to Façade ratio $20 \%$, equivalent to $1.80 \mathrm{~m}^{2}$.

30: Window to Façade ratio $30 \%$, equivalent to $2.70 \mathrm{~m}^{2}$.

40: Window to Façade ratio $40 \%$, equivalent to $3.60 \mathrm{~m}^{2}$.

60: Window to Façade ratio $60 \%$, equivalent to $5.40 \mathrm{~m}^{2}$.

80: Window to Façade ratio $80 \%$, equivalent to $7.20 \mathrm{~m}^{2}$.

Room reflectance:

B: Bright room: Bright room: Room surfaces with an average reflectance of $75 \%$.

D: Dark room: Bright room: Room surfaces with an average reflectance of $40 \%$.

These variables have been established according to the most common parameters of shape, size and position of the window of a conventional room.

\section{B. Program}

DAYSIM 3.1 is a validated RADIANCE-based daylighting analysis tool that uses a daylight coefficient approach combined with the Perez all-weather sky model [23] to predict the amount of daylight in and around buildings, based on direct normal and diffuse horizontal irradiances taken from a climate file. DAYSIM was developed to provide a more efficient calculation of illuminance or luminance time series under varying sky conditions than that originally provided by RADIANCE. This lighting software has been validated by several researchers [24], [25] who have determined accuracy by applying the CIE test cases [24]. The calculation parameters used by this program in this research are shown in Table I.

TABLE I: CALCULATION PARAMETERS OF DAYSIM 3.2

\begin{tabular}{|l|l|l|}
\hline \multirow{3}{*}{$\begin{array}{l}\text { Radiance } \\
\text { Parameters }\end{array}$} & Ambient Bounces & 7 \\
\cline { 2 - 3 } & Ambient Divisions & 1500 \\
\cline { 2 - 3 } & Ambient Super-samples & 100 \\
\cline { 2 - 3 } & Ambient Resolution & 300 \\
\cline { 2 - 3 } & Ambient Accuracy & 0.05 \\
\cline { 2 - 3 } & Limit Reflection & 10 \\
\cline { 2 - 3 } & Specular Threshold & 0.0000 \\
\hline & Specular Jitter & 1.0000 \\
\hline & Limit Weight & 0.0040 \\
\cline { 2 - 3 } & Direct Jitter & 0.0000 \\
\cline { 2 - 3 } & Direct Sampling & 0.2000 \\
\cline { 2 - 3 } & Direct Relays & 2 \\
\cline { 2 - 3 } & Direct Pretest Density & 512 \\
\hline
\end{tabular}

\section{SKY Conditions}

The main two locations of the room model correspond to London, UK at $50^{\circ}$ north latitude under predominantly overcast skies and Madrid, Spain, at $40^{\circ}$ north latitude under mainly intermediate skies. All trials relating to size of the window are developed under these weather conditions.

In order to illustrate the impact of variation of daylight availability, two complementary locations were chosen for a further trial: Rabat, Morocco, near $30^{\circ}$ north latitude under mainly clear skies and Mexico DF, Mexico, close to $20^{\circ}$ north latitude under predominantly clear skies.

Weather data for all locations are taken from the Energy Plus reference [25], based on direct normal and diffuse horizontal irradiances and the sky model defined by Perez et al. [26].

\section{Calculation Conditions}

The calculation of circadian stimulus have been developed considering an occupancy hours from 8:00 am to 5:00 pm, with one break to lunch. The illuminance threshold to meet a value of $50 \%$ is 522 lux. The blind control is active, so the users avoid direct sunlight on work plane.

In order to determine the CS values, Rea et al.'s model of photo transduction by the human circadian system was used to estimate CLA from the source spectral power distribution (SPD) and the illuminance levels obtained at each study point, using the following formula: 


$$
C S=0.7 *\left(1-\frac{1}{1+\left(\frac{C L_{A}}{355.7}\right)^{1.1026}}\right)
$$

CS is directly proportional to the predicted levels of light-induced nocturnal melatonin suppression from threshold to saturation, assuming a pupil size of $2.3 \mathrm{~mm}$ and the duration of exposure of $1 \mathrm{~h}$.

For the present study, CS autonomy was defined as the percentage of days in the year when CS is equal to or greater than 0.50 for at least $1 \mathrm{~h}$ in the morning. This corresponds to the half saturation constant for acute melatonin suppression. It was hypothesized that achieving this half maximum saturation would be a minimal amount needed to promote circadian entrainment.

Using a CS calculator based upon the model of photo
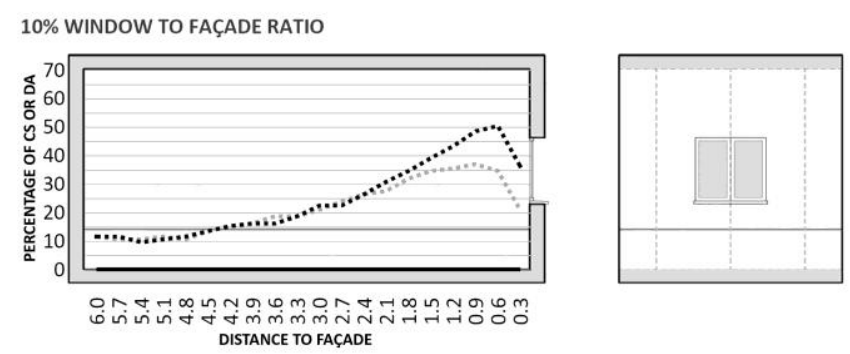

DISTANCE TO FAÇADE
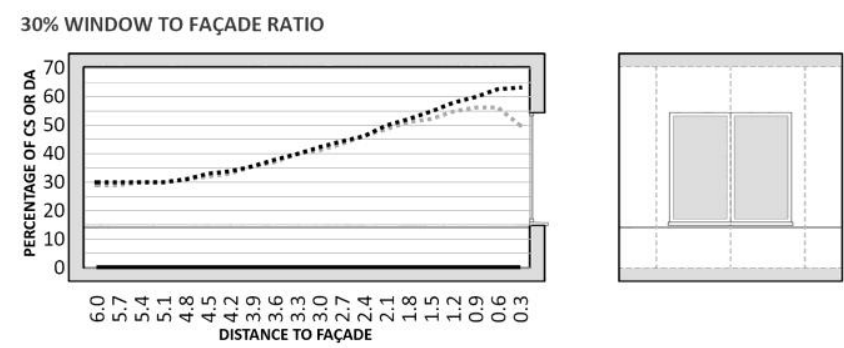
DISTANCE TO FAÇADE

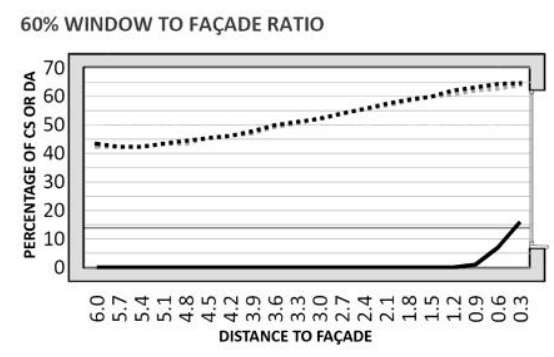

.... SIDE CIRCADIAN STIMULUS (CS)

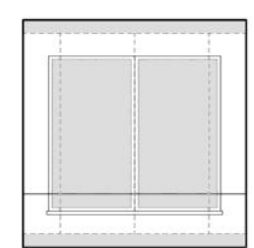

.... CENTER CIRCADIAN STIMULUS (CS)
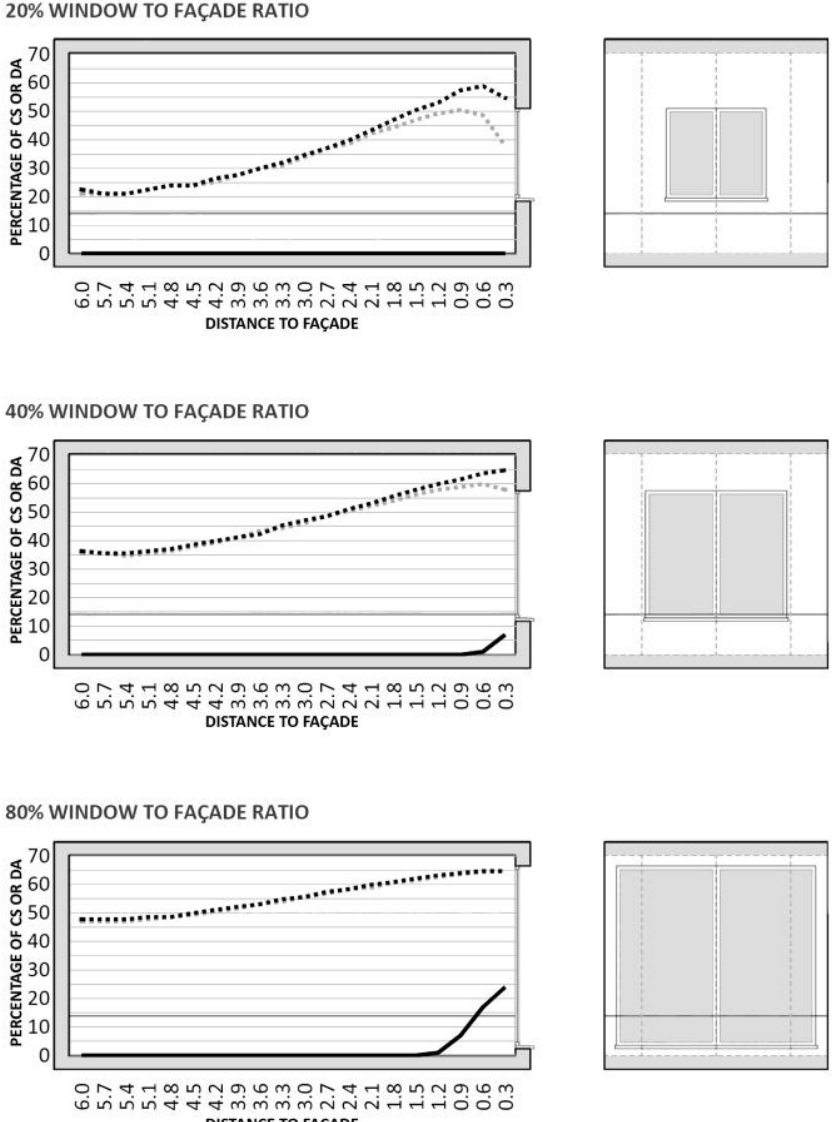
of CIE Standard Illuminant D65 needed to meet a CS of 0.50 corresponds to 522 photopic lux at the eye.

In order to have an illuminance-based glare analysis, maximum daylight autonomy was defined, for the present study, as the percentage of the year when the illuminance reaches a high value due to the incidence of sunlight, effectively a "glare zone" where sunlight falls inside the room. The glare from direct sun may be too high for patients' comfort, although it can be beneficial for occupants' health. The maximum daylight autonomy was calculated by AYSIM 3.1 using the daylight autonomy calculation with a threshold of 5000 lux.

Fig. 2. Circadian Stimulus values for rooms with square windows with surface between 10 and $80 \%$ of the façade and high reflectance surfaces. Room located in London, UK.

\section{CAlculation}

Following the methodology described, the circadian stimulus values are shown in Fig. 2 for the London location. A proper value of circadian stimulus is located between 50 and $100 \%$.

The measurement of the maximum daylight autonomy is also shown in Fig. 2.

As can be noted in Fig. 2, the rooms with a square window equal to $10 \%$ of the façade do not reach a proper value of circadian stimuli. Moreover, in the case of the rooms with a window size equal to $20 \%$ of the façade area, the circadian stimuli reaches a value close to $60 \%$ in the area near the window.

On the other hand, window-to-façade ratios equal or higher than $60 \%$ reach a proper value of circadian stimuli in the entire work plane, providing a good circadian entrainment for occupants.

As can be observed in Fig. 3, the reflectance of the inner surfaces of the room affects drastically to the circadian stimulus measured at the back of the room. A value higher to $50 \%$ is only reach in the zone near the façade, regarding de window size. Therefore, it can be conclude that the reflectance of surfaces is decisive to provide a good circadian stimuli value. 
$10 \%$ WINDOW TO FAÇADE RATIO

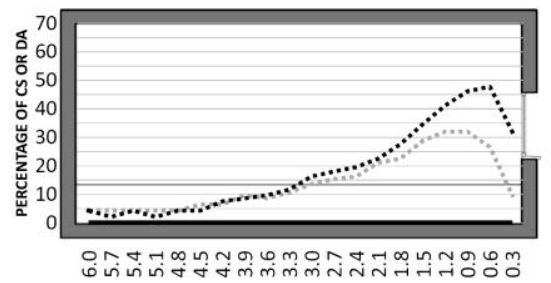

DISTANCE TO FAÇADE

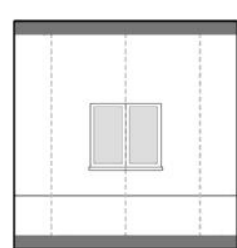

$20 \%$ WINDOW TO FAÇADE RATIO

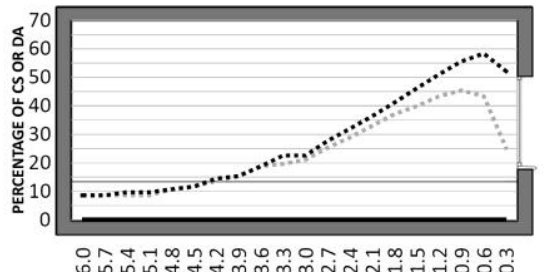

DISTANCE TO FAÇADE

$40 \%$ WINDOW TO FAÇADE RATIO

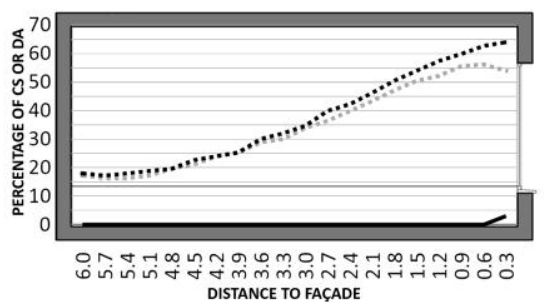

$80 \%$ WINDOW TO FAÇADE RATIO

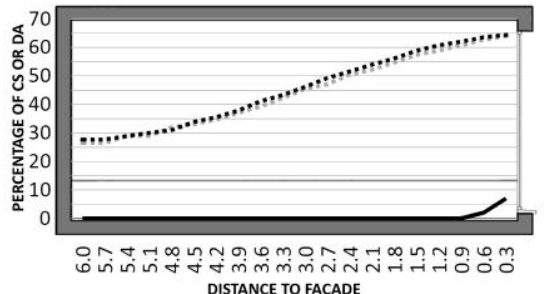

-MAXIMUM DAYLIGHT AUTONOMY(DA)
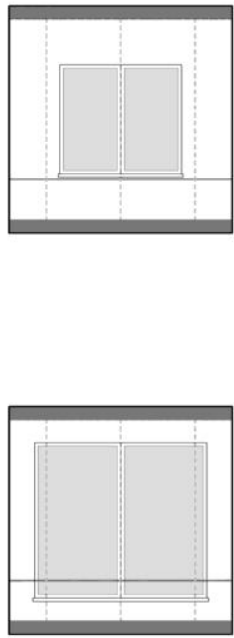

..... CENTER CIRCADIAN STIMULUS (CS)

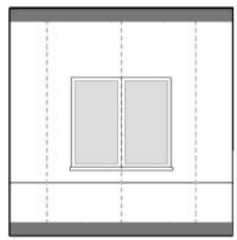

$30 \%$ WINDOW TO FAÇADE RATIO

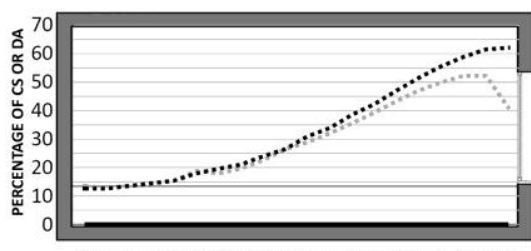

DISTANCE TO FAÇADE

$60 \%$ WINDOW TO FAÇADE RATIO
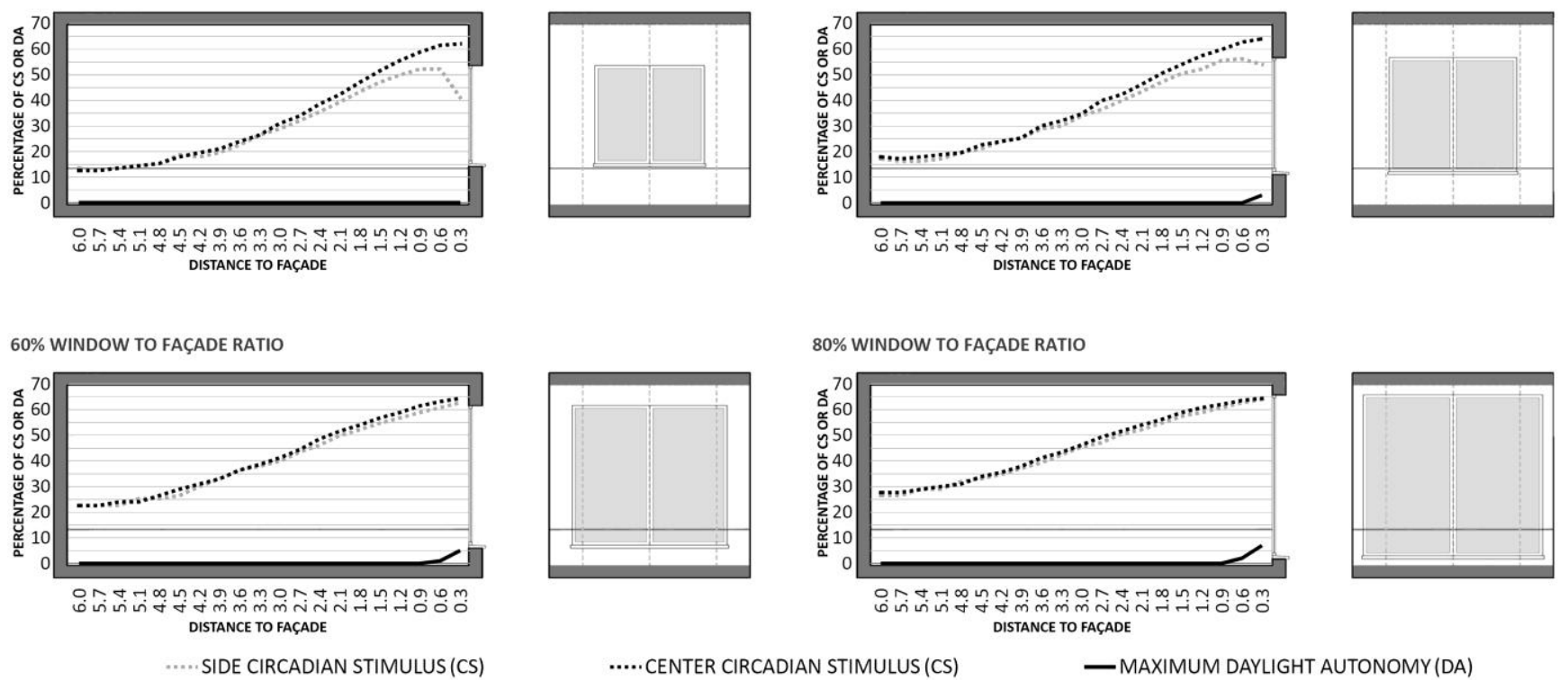

Fig. 3. Circadian Stimulus values for rooms with square windows with surface between 10 and $80 \%$ of the façade and low reflectance surfaces. Room located in London, UK.
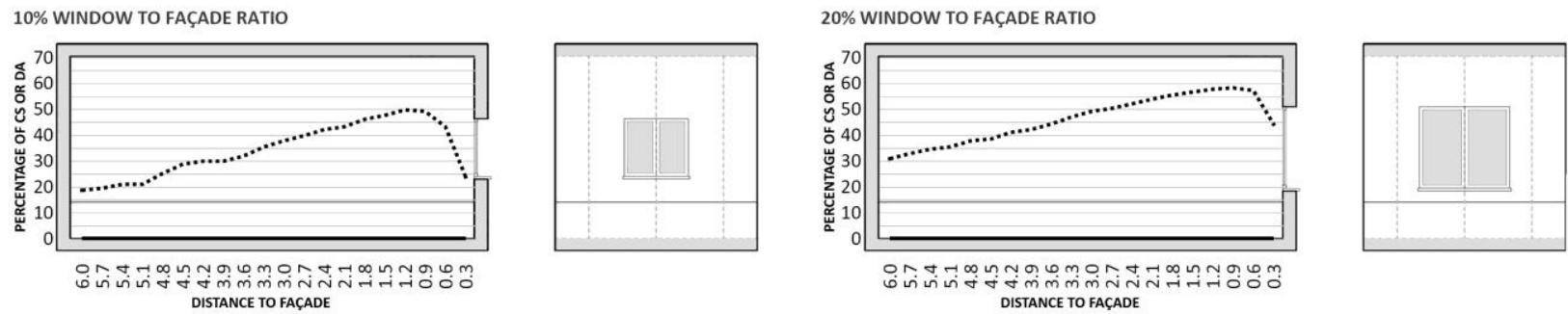
DISTANCE TO FAÇADE

$30 \%$ WINDOW TO FAÇADE RATIO
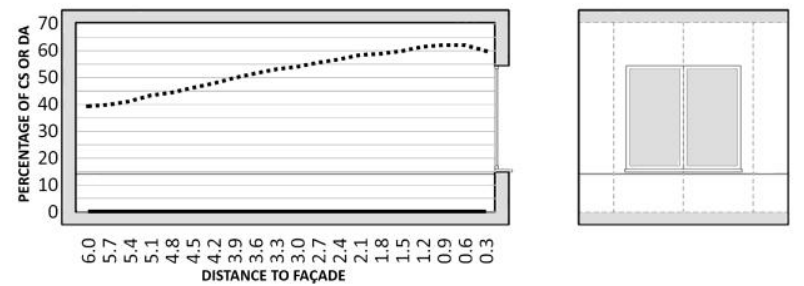

40\% WINDOW TO FAÇADE RATIO
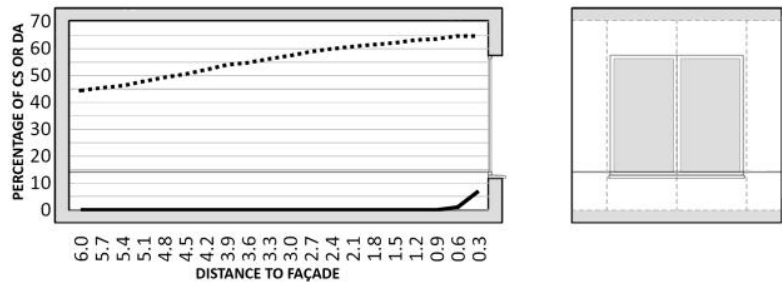
DISTANCE TO FACADE

$60 \%$ WINDOW TO FAÇADE RATIO
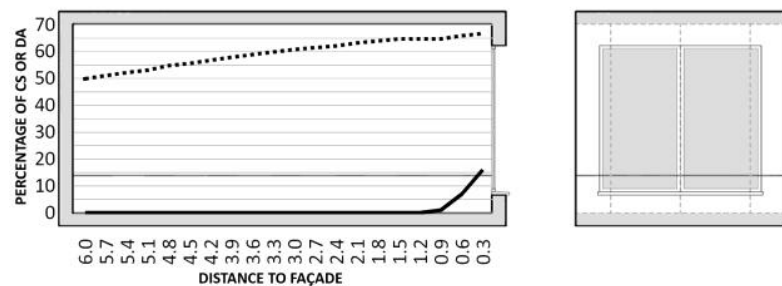

.... CIRCADIAN STIMULUS (CS)

$80 \%$ WINDOW TO FACADE RATIO
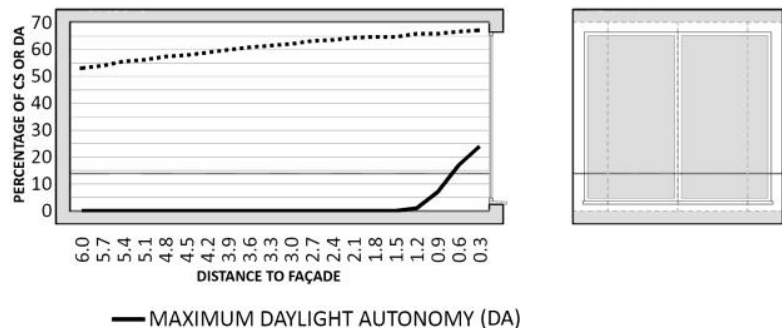

Fig. 4. Circadian Stimulus values for rooms with square windows with surface between 10 and $80 \%$ of the façade and high reflectance surfaces. Room located in Madrid, Spain. 
$10 \%$ WINDOW TO FAÇADE RATIO

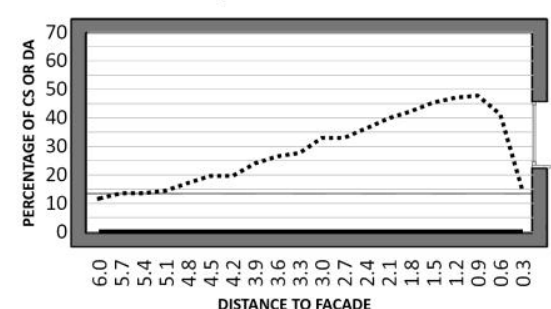

DISTANCE TO FAÇADE

$30 \%$ WINDOW TO FAÇADE RATIO

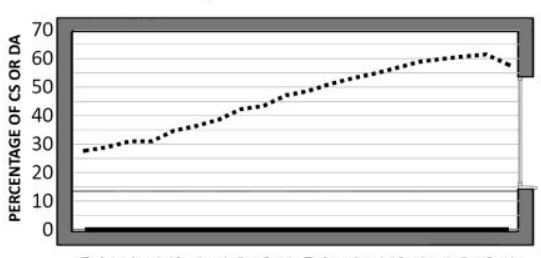

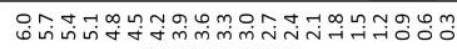
DISTANCE TO FAÇADE

$60 \%$ WINDOW TO FAÇADE RATIO

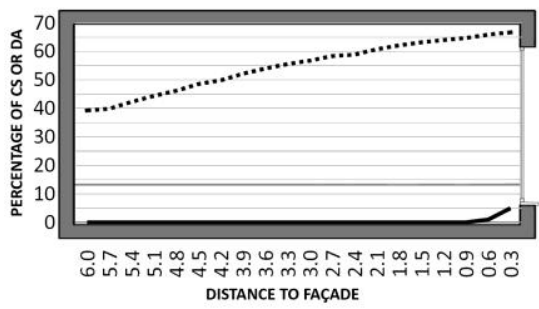

.... CIRCADIAN STIMULUS (CS)

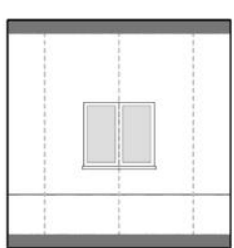

$20 \%$ WINDOW TO FAÇADE RATIO

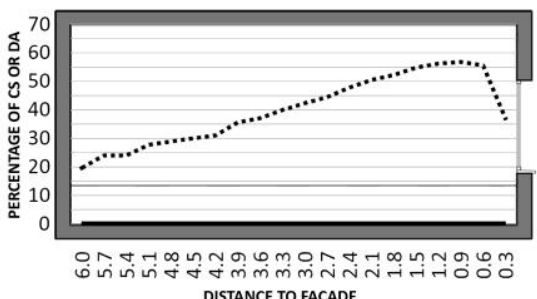

DISTANCE TO FAÇADE

40\% WINDOW TO FAÇADE RATIO

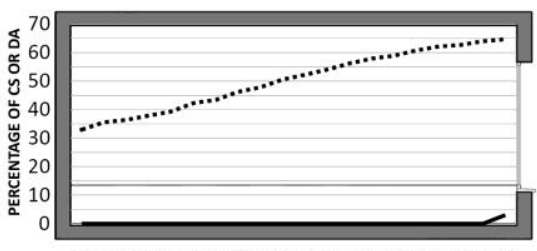

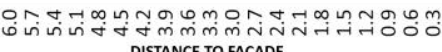

$80 \%$ WINDOW TO FAÇADE RATIO
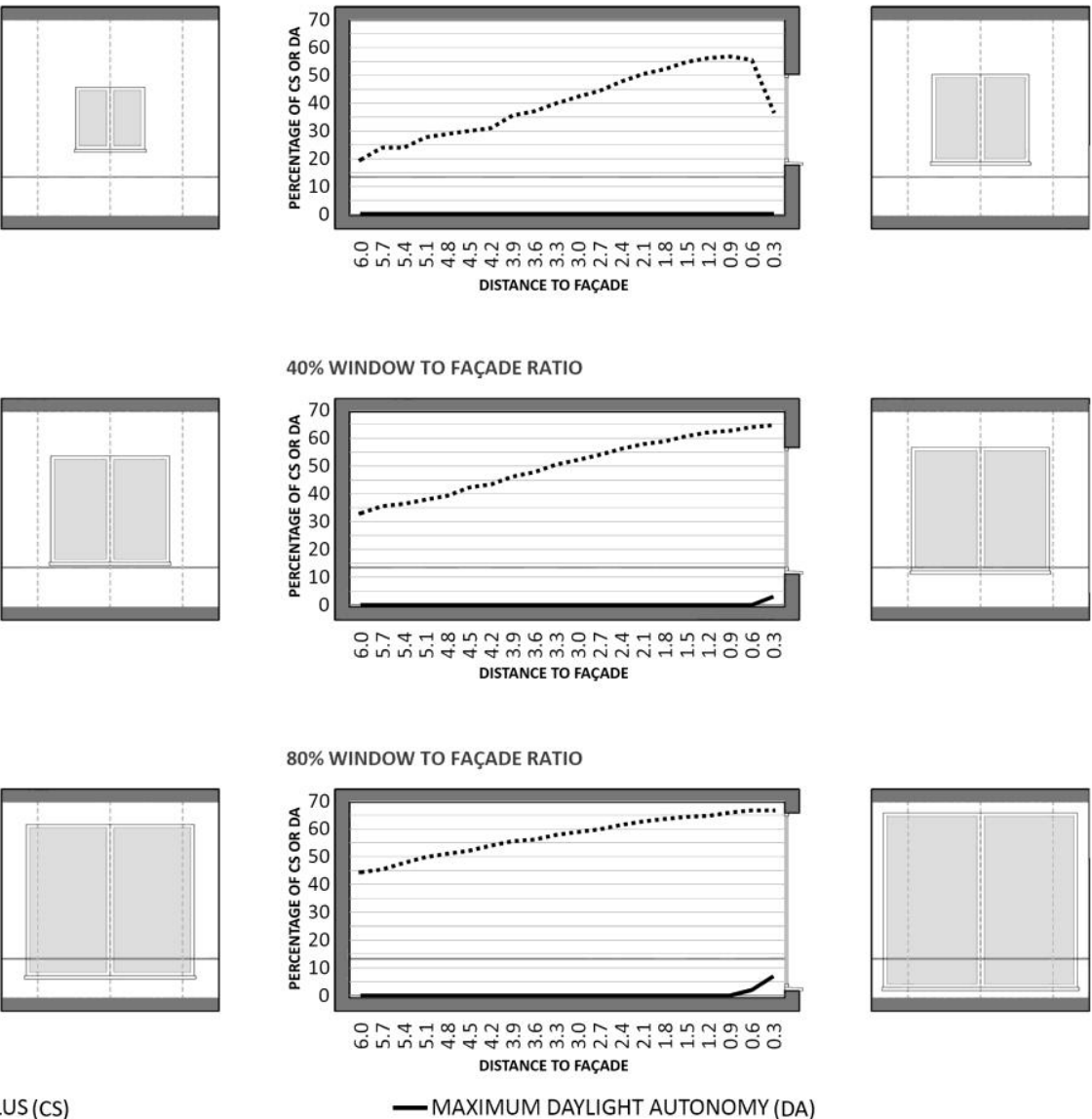

- MAXIMUM DAYLIGHT AUTONOMY (DA)

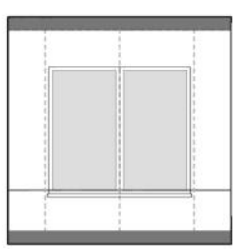

Fig. 5. Circadian Stimulus values for rooms with square windows with surface between 10 and $80 \%$ of the façade and low reflectance surfaces. Room located in Madrid.

According to the locations defined in the methodology, Fig. 4 shows the circadian stimuli values for the Madrid location.

As can be noted, in the case of Madrid location and high reflectance surfaces, the proper circadian stimuli value is reached easily in the entire work plane for rooms with a window-to-façade ratio equal or higher than $40 \%$. It can be deduced that the weather conditions are, therefore, decisive to determine the proper window size in order to get the circadian entrainment.

On the other hand, considering the same location and as can be deduced from Fig. 5, the reflectance of the inner surfaces produces a reduction of the circadian stimuli values in the back of the room. However, this decrease is lesser than that observed in the case of London location. Therefore, it can be concluded that the circadian stimulus in the back of the room depend on the reflectance of the inner surfaces and the weather average conditions, as well as the window size.

Whatever the case, a window-to-façade ratio equal or higher than $60 \%$ provide a proper circadian stimulus in the entire work plane, considering the Madrid location. As can be deduced from the previous figures, there is a minimum window-to-façade ratio to determine a proper circadian stimulus in the zone near the façade or in the entire room.

\section{ANALYSIS OF RESUlTS}

After performing the trials and determining the quantification of circadian stimulus, the assessment of the circadian stimulus autonomy is developed.
As explained above, the circadian stimulus autonomy was defined as the percentage of days in the year when CS is equal to or greater than 0.50 for at least $1 \mathrm{~h}$ in the morning. It was hypothesized that achieving this half maximum saturation would be a minimal amount needed to promote circadian entrainment.

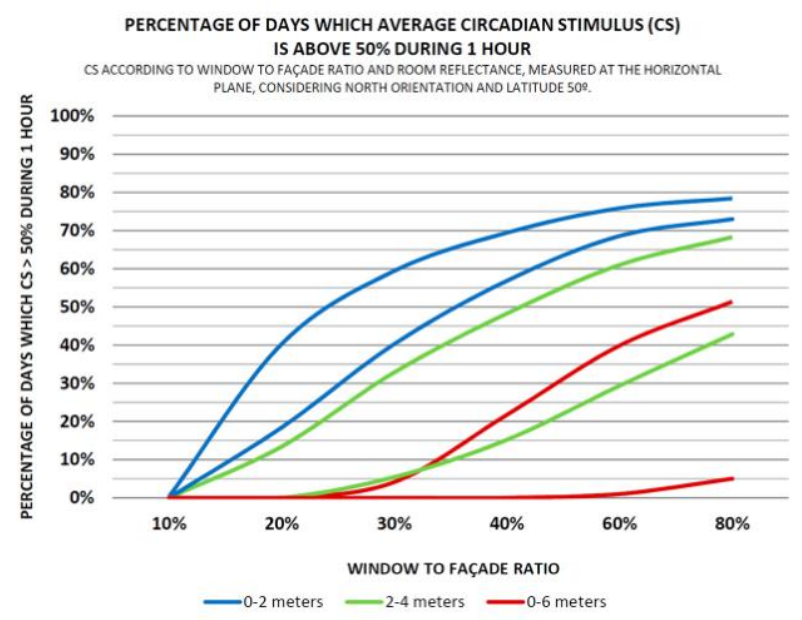

Fig. 6. Circadian Stimulus Autonomy (CSA) according to London location, latitude $50^{\circ}$ and mainly overcast skies.

The circadian stimulus autonomy has been defined as the daylight autonomy according to a threshold of 522 lux, considering an occupancy hours from 8:00 am to 5:00 pm.

The CS autonomy values are assessed in four locations, as explained in the methodology: London, UK at $50^{\circ}$ north 
latitude under predominantly overcast skies, Madrid, Spain, at $40^{\circ}$ north latitude under mainly intermediate skies, Rabat, Morocco, near $30^{\circ}$ north latitude under mainly clear skies and Mexico DF, Mexico, close to $20^{\circ}$ north latitude under predominantly clear skies.

CS autonomy is shown as a function of window-to-façade ratio. The upper and lower boundary of each zone represents high (70\%) and low (40\%) mean surface reflectance values, respectively. The blue hatch represents CS autonomy in the zone near the façade, from 0 to $2 \mathrm{~m}$; the green hatch is the zone from 2 to $4 \mathrm{~m}$; and the red hatch is the zone in the back of the room, from 4 to $6 \mathrm{~m}$ from the façade.

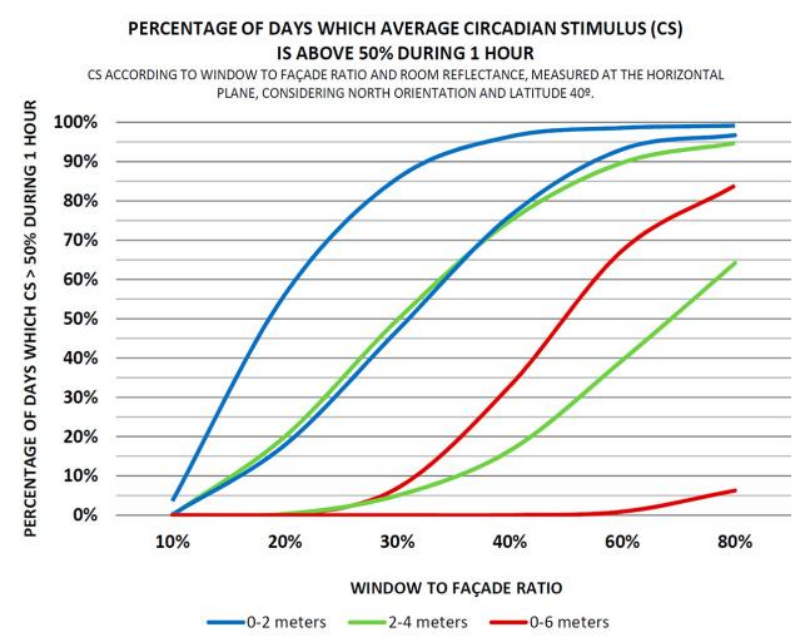

Fig. 7. Circadian Stimulus Autonomy (CSA) according to Madrid location, latitude $40^{\circ}$ and mainly intermediate skies.

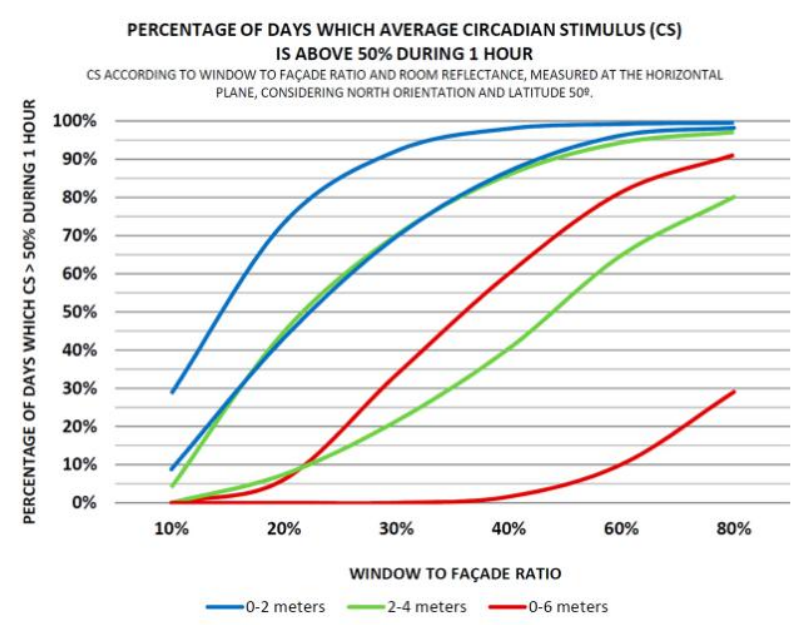

Fig. 8. Circadian Stimulus Autonomy (CSA) according to Rabat location, latitude $30^{\circ}$ and mainly clear skies.

As can be observed in the previous figures, the latitude and the weather conditions are decisive to determine the circadian stimulus autonomy (CSA). Accordingly, the reflectance of the inner surfaces of the room also defines the values obtained.

Studying the case of London location, observed in Fig. 6, at latitude $50^{\circ}$ and predominantly overcast skies, it can be deduced that a window-to-façade ratio equal or higher than $30 \%$ provides a CSA higher than $50 \%$ in the zone near the façade, enough to promote the circadian entrainment. However, a window size higher than $60 \%$ is necessary to obtain a CSA value higher than $50 \%$, considering high reflectance surfaces.

As can be deduced from Fig. 7, the circadian stimulus obtained for Madrid location, at latitude $40^{\circ}$ and intermediate skies, are considerably higher than those observed for London location. A window-to-façade ratio of $20 \%$ is enough to promote a proper value of CSA in the zone close to the window, while a window size equal or higher than $60 \%$ serves to get a CSA value higher than $50 \%$ in the entire room, considering an intermediate value of the reflectance.

As noted in Fig. 8, according to the Rabat location, at latitude close to $30^{\circ}$ and predominantly clear skies, a window-to-façade ratio of $20 \%$ is enough to promote a value of CSA higher than $50 \%$ in the zone close to the façade, while a window size equal or higher than $40 \%$ serves to get a proper CSA value in the entire room considering a high reflectance of the inner surfaces.

Finally, as can be seen in Fig. 9, considering the location of Mexico DF, at latitude close to $20^{\circ}$ and mainly clear skies, a window-to-façade ratio of $20 \%$ is enough to promote a value of CSA higher than $50 \%$ from the façade to the middle zone of the room, while a window size equal or higher than $40 \%$ serves to get a proper CSA value in the entire room considering an intermediate value of the reflectance of the surfaces.

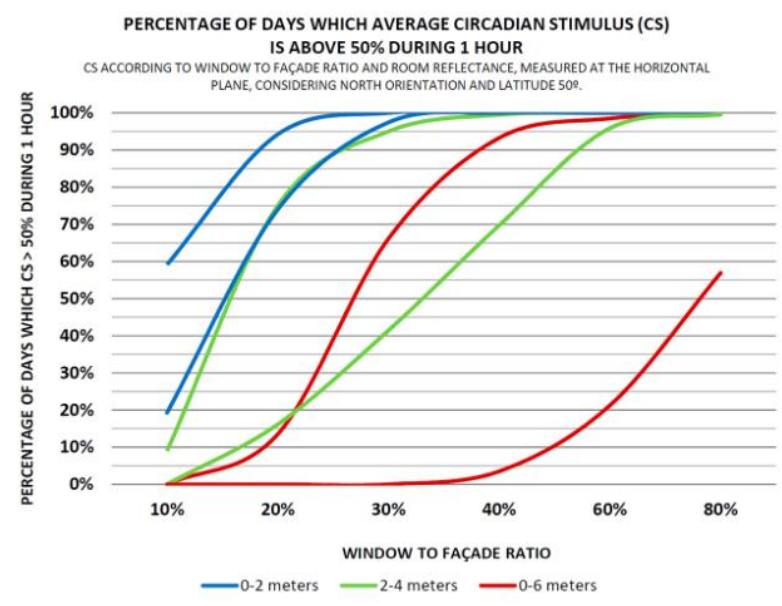

Fig. 9. Circadian Stimulus Autonomy (CSA) according to Mexico DF location, latitude $20^{\circ}$ and mainly clear skies.

\section{CONCLUSIONS}

The analysis of results has assessed the variation of the circadian stimuli, which determines the synchronization of the circadian rhythm, depending on the geometry of the opening, reaching several conclusions that can be applied to window design. Additionally, the study of the variation of the reflectance of the inner surfaces of the room allows determining the circadian stimulus based on this variable.

The quantification of the circadian stimulus serves as a basis for the analysis of results. However, it also offers a database of the natural illumination produced by a window within a room. Accordingly, the most representative calculation models of current architecture have been chosen for simulation, using the most common window designs. Obviously, this research does not cover all possible hypotheses, but aims to show the most frequent cases study under the most adverse sky conditions. 
In addition, the circadian stimulus autonomy has been defined for different window size and locations. The circadian stimulus autonomy was defined as the percentage of days in the year when CS is equal to or greater than 0.50 for at least $1 \mathrm{~h}$ in the morning. This corresponds to the half saturation constant for acute melatonin suppression. It was hypothesized that achieving this half maximum saturation would be a minimal amount needed to promote circadian entrainment.

\section{REFERENCES}

[1] S. Treado, G. Gillette, and T. Kusuda, "Daylighting with windows, skylights, and clerestories," Energy and Buildings, vol. 6, pp. 319- 330, 1984.

[2] D. H. W. Li, "A review of daylight illuminance determinations and energy implications," Applied Energy, vol.87, pp. 2109-2118, 2010.

[3] I. Acosta, C. Munoz, M.A. Campano, and J. Navarro, "Analysis of daylight factors and energy saving allowed by windows under overcast sky conditions," Renewable Energy, vol.77, pp. 194-207, 2015.

[4] C. M. Munoz, P. M. Esquivias, D. Rangel, I. Acosta, and J. Navarro, "Climate-based daylighting analysis for the effects of location, orientation and obstruction," Lighting Research and Technology, vol. 46, pp. 268-280, 2013

[5] H. H. Alzoubi and A. H. Al-Zoubi, "Assessment of building façade performance in terms of daylighting and the associated energy consumption in architectural spaces: Vertical and horizontal shading devices for southern exposure facades," Energy Conversion and Management, vol. 51, pp. 1592-1599, 2010.

[6] A. Villalba, A. Pattini, and E. Correa, "An approach to urban tree daylight permeability simulation using models based on louvers," Building and Environment, vol. 73, pp. 75-87, 2014.

[7] L. Sanati and M. Utzinger, "The effect of window shading design on occupant use of blinds and electric lighting," Building and Environment, vol. 64, pp. 67-76, 2013.

[8] P.R. Boyce, "The impact of light in buildings on human health," Indoor and Built Environment, vol. 19, pp. 8-20, 2010.

[9] CIE, International lighting vocabulary, Commission Internationale de l'Éclairage, 2011.

[10] CIBSE, Daylighting and Window Design, CIBSE LG10. London: Chartered Institution of Building Services Engineers, 1999.

[11] J. A. Love, "Determination of the daylight factor under real and overcast skies," Journal of the Illuminating Engineering Society, vol. 22, no.2, pp. 176-182, 1993.

[12] C. F. Reinhart, J. Mardaljevic, and Z. Rogers, "Dynamic daylight performance metrics for sustainable building design," Leukos, vol. 3, no. 1, pp. 7-31, 2006

[13] P. R. Boyce and K. A. G. Smet, "Better metrics for better lighting" Lighting Research and Technology, vol. 46, pp. 619-636, 2013.

[14] R. P. Leslie, L. C. Radetsky, and A. M. Smith, "Conceptual design metrics for daylighting," Lighting Research and Technologies, vol. 44, pp. 277-290, 2012.
[15] M. G. Figueiro, J. A. Brons, B. Plitnick, B. Donlan, R. P. Leslie, and M. S. Rea, "Measuring circadian light and its impact on adolescents," Lighting Research and Technology, vol. 43, pp. 201-215, 2011.

[16] A. Barroso, K. Simons, and P. Jager, "Metrics of circadian lighting for clinical investigations," Lighting Research and Technology, vol. 46, pp. 637-649, 2014

[17] M. S. Rea, M. G. Figueiro, J. D. Bullough, and A. Bierman, "A model of phototransduction by the human circadian system," Brain Research Reviews, vol. 50, no. 2, pp. 213-228, 2005.

[18] I. Acosta, R. Leslie, and M. G. Figueiro, "Analysis of circadian stimulus allowed by daylighting in hospital rooms," Lighting Research and Technology.

[19] I. Kriszbacher, J. Bódis, I. Boncz, A. Koppan, and M. Koppan, "The time of sunrise and the number of hours with daylight may influence the diurnal rhythm of acute heart attack mortality," International Journal of Cardiology, vol. 140, pp. 118-120, 2010

[20] J. D Bullough, M. S. Rea, and M. G. Figueiro, "Of mice and women: Light as a circadian stimulus in breast cancer research," Cancer Causes and Control, vol. 17, pp. 375-383, 2006.

[21] H. H. Alzoubi and S. M. Al-Rqaibat, "The effect of hospital design on indoor daylight quality in childrensection in King Abdullah University hospital, Jordan," Sustainable Cities and Society, vol. 14, pp. 449-455, 2014.

[22] J. H. Choi, L. O. Beltran, and H. S. Kim, "Impacts of indoor daylight environments on patient average length of stay (ALOS) in a healthcare facility," Building and Environment, vol. 50, pp. 65-75, 2012.

[23] R. Perez, R. Seals, and J. Michalsky, "All-weather model for sky luminance distribution - Preliminary configuration and validation," Solar Energy, vol. 50, no. 3, pp. 235-245, 1993.

[24] C. F. Reinhart and O. Walkenhorst, "Validation of dynamic RADIANCE-based daylight simulations for a test office with external blinds," Energy and Buildings, vol. 33, no. 7, pp. 683-697, 2001.

[25] I. Acosta, C. M. Munoz, P. M. Esquivias, D. Rangel, and J. Navarro, "Analysis of the accuracy of the sky component calculation in daylighting simulation programs," Solar Energy, vol. 119, pp. .54-67, 2015.

[26] CIE, Test cases to assess the accuracy of lighting computer programs, Commission Internationale de l'Éclairage, 2006.

[27] Lawrence Berkley National Laboratory, EnergyPlus Engineering Reference. The reference to EnergyPlus Calculations, Lawrence Berkeley National Laboratory, Technical report, 2012.

[28] CIE, Spatial Distribution of Daylight - CIE Standard General Sky, Commission Internationale de l'Éclairage, 2003.

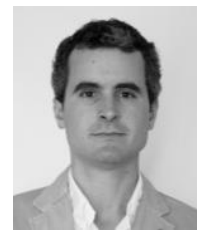

I. Acosta is a professor at the Department of Building Construction, University of Seville, Spain. $\mathrm{He}$ is a member of the research group TEP-130 which is focused on sustainability, energy efficiency, lighting and acoustics related to building design

The author belongs to the Instituto Universitario de Arquitectura y Ciencias de la Construcción.

He main research field of the author is the study of daylighting and its relationship with the architectural design. Most of the papers developed by the author analysis the energy savings in electric lighting produce by the proper use of daylighting, the study of predictive methods to determine the illuminance in courtyards and the measurement of the circadian stimulus 